has developed a highly effective method for eluding the immune system of the host, known as 'antigenic variation'. The disease is characterised by waves of illness, reflecting rapid growth of the parasite, followed by remission engendered by an immune response, followed by sequential emergence of antigenically different organisms.

Because the organism has not yet been grown in culture, it is not known by what genetic or regulatory mechanism it manages to change its surface characteristics to evade the immune system. Two different lines of research for potential vaccination are, however, being followed. The first would involve modifying the immune system of the host so that it would react quickly to wipe out the second appearance of the organism before it reaches sufficient numbers to produce disease. Following the recent isolation of the major antigenic surface molecule, the second would involve the production of a "cocktail" vaccine containing a mixture of antigens from the most common variants to combat the different forms of the organism. Both require better characterisation of the organism and its antigens.

- There are many similarities between the animal and human parasitic diseases, such as Chagas disease and malaria, and there are consequently common research problems and strat- egies. Chagas disease, caused by the organism Trypanosoma cruzi, affects 30 million people, chiefly in Latin America. Ten per cent of its victims, virtually all children, die from an acute disease, while the rest develop a chronic illness with invasion and destruction of heart and smooth muscle. It frequently ends in sudden death. Although there is no effective treatment at present, an irradiated vaccine has been produced from parasites grown in animal cell cultures. It provides virtually $100 \%$ protection to massive challenge in susceptible mice, which are killed by a single virulent trypanosome.

- Two hundred and fifty milion people now suffer from malaria worldwide, and at least a million people die from the disease in Africa alone. Two successful types of experimental vaccines against different forms of the organism have been produced, but practical limitations on the quantity of these vaccines preclude either of them from being useful on a large scale. One line of research is aimed at defining the nature of the protective antigens so that synthetic antigens could be developed as potential vaccine material.

There are major scientific questions to be understood and problems to be overcome that will require contributions by molecular biologists and geneticists as well as parasitologists and immunologists, and at this stage even if increased support for research were forthcoming, it would be foolish to guarantee that inexpensive and effective vaccines and drugs would result. Even if some were to be developed, there would remain two further serious problems. Although effective vaccines, particularly against African trypanosomiasis, would offer the possibility of opening vast areas in the tsetse belt to cattle production, without thoughtful assessment of the ecological consequences and intelligent regulation, marginal areas of the Sahel and tropical Africa could be destroyed by overgrazing. The second problem is the lack of an effective health infrastructure in the developing countries. There is a critical need for developing health services and training adequate health manpower to provide basic information and care for the health needs of the human and animal populations.

At the very least, it is worth considering what could be accomplished simply by supporting studies on the evidemiology of the animal parasitic diseases. It is an activity which could involve large numbers of untrained young people in an important scientific and educational enterprise. It would serve to develop a pool of talent from which the best could be selected for more advanced training in the health sciences and services.

\section{Behind the politics of influenza}

The idea of the United States government footing the bill to prevent the American population falling sick makes President Ford's request for funds to attempt a mass inoculation against flu something more than a medical issue in this election year. From Washington, Colin Norman gives the background

ON FEBRUARY 3, a young army recruit stationed at Fort Dix, New Jersey, came down with what seemed like a typical case of influenza. But the next day, while on a training march, he collapsed and died. His death sparked off an extraordinary series of events, culminating last week in the launching of the most extensive and controversial mass inoculation campaign ever undertaken in the United States.

The cause of the soldier's death turned out to be pneumonia, but a virus isolated from his respiratory tract immediately set alarm bells ringing in public health laboratories around the world. It was found to be a strain of influenza virus, commonly found in swine, which had not been involved in human infections for nearly 50 years. The virus, moreover, is very similar to the strain which caused the most serious flu pandemic in modern history, the 1918-19 outbreak which swept around the world killing some 20 million people.

Though only 12 other cases of swine flu were subsequently confirmed at Fort Dix, a massive monitoring effort on the base found antibodies to the flu strain in the blood of some 500 recruits, suggesting that they had been infected with swine flu during the outbreak. If the young recruit hadn't died, the outbreak would simply have been put down to the so-called Victoria/A strain which has been widespread in the United States this winter, but the isolation of the swine virus may have provided advance warning of a possible new flu pandemic next winter.

Because swine flu hasn't been abroad in the human population since the late $1930 \mathrm{~s}$, nobody under the age of 50 has any antibodies to guard against it. And it is likely that even those who do have antibodies are not protected against the disease. Thus, if the Fort Dix outbreak is not just a freak, isolated event, the virus could spread like wildfire through an unprotected population. $\mathrm{Dr}$ Edwin Kilbourne, a leading flu researcher at Mount Sinai School of Medicine in New York, said last week, for example, that "our thought is that probably the virus is seeded now in foci around the country, and when winter comes we will see it again".

For several weeks after the virus was isolated and identified, committees of scientists and government officials met at the US government's Center for Disease Control in Atlanta, Georgia, to decide what, if anything, should be done to counter the potential threat. Last week, they decided to recommend a massive inoculation effort against the virus, and President Ford appeared at a press conference, flanked by two of the most well known scientists in the United States-Jonas Salk and Albert Sabin-to announce that he is requesting $\$ 135$ million from Congress for a crash programme to inoculate every man, woman and child in the United States by the end of November. 
The decision was immediately controversial. Officials from the World Health Organisation expressed surprise, some scientists argued that since there's no definite evidence that the Fort Dix outbreak has spread there is no need for a massive inoculation campaign, and there have even been dark hints that the whole thing is an election-year ploy to attract votes. Nevertheless, it can reasonably be argued that Mr Ford had little choice in the matter.

\section{One-jump-ahead virus}

The influenza A virus is an amazing organism, which has managed to evade man's attempts to keep it in check for three decades. Its ability to cause epidemics lies in its extraordinary capacity to stay one jump ahead of the body's natural defence mechanisms by changing its genetic makeup every few years. (Two other classes of influenza virus, designated $\mathbf{B}$ and $\mathbf{C}$, are rather less elusive, however.) When a person is infected by an influenza virus he develops antibodies which will give immunity from subsequent reinfection, but if the virus undergoes a slight genetic change, the antibodies often won't recognise it and the virus can slip past the body's defences and cause disease. The flu virus's ability to change its character is also the reason why attempts to develop vaccines against flu have been relatively disappointing -vaccines developed against one year's flu virus are often ineffective against a modified strain which may appear the following year.

Aside from those small elusive changes, the influenza virus is also capable of major genetic shifts. Every so often, a radically new variation of influenza virus emerges and, because there is no natural resistance to it at all, it can cause major pandemics. The last such pandemic occurred in 1968

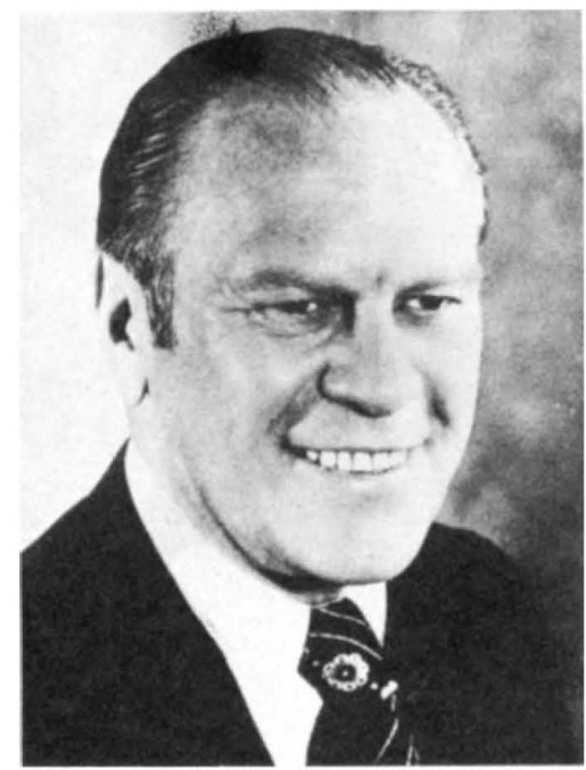

President Ford : requesting \$135 million from a strain first isolated in Hong Kong (hence its popular designation as Hong Kong Flu); another worldwide epidemic occurred in 1957 from a strain which first appeared in Asia.

If, as seems to happen, pandemics appear in roughly 10-year intervals, a radically new flu strain can be anticipated in the late 1970s. The Fort Dix swine flu virus may be that strain. If so, it would be the first time that the world has had advance warning of a pandemic, and that warning could provide time for preventive action. But the evidence is far from conclusive; hence the controversy over Mr Ford's decision to launch a mass inoculation campaign.

Following the isolation of swine flu virus at Fort Dix, a massive study was conducted to see whether the virus is showing up anywhere else in the United States. No other cases were found, and the virus also seems to have disappeared at the army camp. It is therefore possible that the outbreak was a freak event which suddenly ended through unknown causes. But, on the other hand, it is possible that the virus has been seeded in the population and will re-emerge during next winter's flu season.

Kilbourne notes, for example, that "historically we have never recognised a new (flu virus) variant without a major pandemic following in its wake", and he added that the Asian and Hong Kong flu epidemics "smouldered before they took off" in the United States. Dr Robert B. Crouch, professor of infectious diseases at Baylor College of Medicine, is also not surprised that the Fort Dix outbreak seems to have disappeared. He pointed out that the Asian flu epidemic was first spotted in the United States as an isolated outbreak in Iowa which died off, followed by another isolated outbreak in Pennsylvania, which also disappeared; two months later, the full-fledged epidemic began to appear.

\section{Time barrier}

The problem now, however, is that there's not enough time to wait and see whether other outbreaks of swine fiu occur before taking evasive action. Production of the 200 million flu shots which will be required to inoculate the entire US population must begin immediately or the programme won't be completed before next winter. Thus Ford asked Congress last week for funds to begin manufacturing vaccines from the Fort Dix strain as soon as possible, with the goal of inoculating high risk people (the elderly and infirm) by late summer, and the rest of the population by November.

Some scientists have argued, however, that even if the virus does reappear next winter, there is no need to mount a major campaign against it now. Dr Sidney Wolfe, head of Ralph Nader's Health Research Group, argues, for example, that the analogies which have been drawn between the Fort Dix strain and the swine flu virus which caused the 1918 pandemic have been greatly overstated. The huge death toll from the 1918 outbreak resulted from secondary infections such as pneumonia, which can now be cured by antibiotics, and so there's no reason to suppose that a new flu pandemic would be as devastating. It should be pointed out, however, that the Hong Kong flu pandemic killed some 20,000 people in the United States and cost more than $\$ 3,000$ million in terms of lost work and medical expenses, antibiotics notwithstanding.

One particularly disturbing, but inevitable, factor is that the vaccine now being developed will only be effective against the Fort Dix swine flu strain, but the Victoria/A strain and an influenza B strain are also expected to reappear next year. People will therefore be receiving flu shots but can still expect to get a variety of influenza, a fact which won't increase public confidence in medical science.

A more alarming possibility, which cannot be dismissed out of hand, is that an entirely new flu strain could emerge in the southern hemisphere during the next few months as the harbinger of a different flu pandemic. In that case, people in the United States could be getting immunized against the wrong pandemic strain.

Be that as it may, President Ford was presented with a problem for which there is really only one solution. Though the evidence is sketchy, it is possible that a pandemic flu strain has been isolated in time to take precautionary action. Mr Ford could gamble that the virus won't reappear and do nothing, in which case he would bear a heavy responsibility if the virus did show up again, or he could ask Congress for $\$ 135$ million as an insurance policy.

Though those involved in the decision vehemently deny that politics played any part, it cannot be denied that if Ford refused to initiate an inoculation program and swine flu became rampant in October, the effect on the November elections could be decisive. By the same token, it is unlikely that Congress will deny the request for the funds.

A statement released last week by Britain's Department of Health in response to developments in the United States said that on present evidence its advisory group on influenza would not be recommending vaccination. The group suggests, however, that it would be a wise precaution to incorporate the new virus into anti-flu vaccine. 